\title{
ANALYSIS OF BUCHAREST'S LAND COVER EVOLUTION OVER A PERIOD OF 33 YEARS USING MULTI-SENSOR DATA
}

\author{
A.-C. Grivei ${ }^{1}$, and M. Datcu ${ }^{12}$, Fellow, IEEE \\ ${ }^{1}$ University Politehnica of Bucharest (UPB), Romania \\ ${ }^{2}$ Remote Sensing Technology Institute, German Aerospace Center (DLR), Germany
}

\begin{abstract}
Past and current EO (Earth Observation) satellite missions have gathered huge amount of data during the past decades. This offers the opportunity to retrieve significant information concerning the evolution of land cover for almost any point of interest (POI) on Earth's surface. This paper presents the evolution of land cover in the administrative area of Bucharest, Romania, over a time span of 33 years. In order to achieve this goal we use data acquired by multiple EO missions such as: Landsat 5 TM (Thematic Mapper), 7 ETM+ (Enhanced Thematic Mapper Plus), 8 OLI/TIRS (Operational Land Imager/Thermal InfraRed Sensor) and Sentinel-2 MSI (MultiSpectral Instrument). We compute several spectral indexes in order to obtain information regarding the surface coverage evolution for categories such as vegetation, water bodies and build up.
\end{abstract}

Index Terms - Landsat, Sentinel-2, land cover evolution

\section{INTRODUCTION}

The percentage of the global population which lives in urban settlements has grown from $33.55 \%$ in 1960 to about $54.29 \%$ in 2016 [1]. As of 2008 the majority 50.49\% of humans live in urban areas and this ascending trend will continue in the future. Overpopulation and pollution have a great impact on the health of humans living in huge metropolises. The urban vegetation component represented by urban forests, lawns, grassland and other recreational greenness has a great impact on the urban ecological environment. Vegetation also has a great impact on the temperatures experienced in the built up zones with a greater impact during summer when average temperatures are higher than the ones in rural or non-anthropized areas. It is shown that urban vegetation abundance (UVA) and urban forest abundance (UFA) are both negatively correlated with land surface temperature (LST)[2].

Large Satellite Image Time Series (SITS), which span multiple decades usually require data from several Earth Observation missions. This in turn can generate issues when

A. C. Grivei e-mail: alex.grivei@ymail.com

M. Datcu e-mail: mihai.datcu@dlr.de. analyzing the processed data. Each sensor has its own particularities which can exhibit different behaviors when computing some spectral indices such as NDVI (Normalized Difference Vegetation Index) or SAVI (Soil Adjusted Vegetation Index) which are commonly used to retrieve information regarding vegetation from Earth Observation data. If the area of interest is an urban area, the image's resolution and the high heterogeneity of the covered land can generate uncertainties regarding the accuracy of the vegetation indexes [3]. With the aid of preprocessing [4] certain datasets such as the ones provided by the Landsat missions can be considered as a unified NDVI set, showing similar absolute variance when seasonality is removed [5]. One of the most recent Earth Observation mission is the European Space Agency's (ESA) Sentinel-2 MSI which aims to provide continuity for the SPOT and Landsat missions.

Large NDVI time series spanning 20 or 30 years covering different parts of the Earth have been used before, but these usually are provided by the same sensor. One such example uses NDVI obtained from Landsat 8 data in order to classify the vegetation and it's evolution in the Tirupati region[6]. Earth observation data is prone to influences from aerosols and water vapor present in the atmosphere. A possible mean of minimizing this issue is through the usage of the maximum value composite (MVC) method prior to computing indexes measurements [7].

The area of interest for our analysis is Bucharest, the capital of Romania. The city has undergone several social, economic and cultural transformations in the past thirty years. Some of the most prominent urban changes which occurred in this period are the replacement of existing structures, such as the re-purposing of old industrial areas, and the reclaiming of agricultural land in the suburban areas [8].

The objective of our paper is to determine the evolution of urban land cover in the past three decades, from 1984 until 2016. We used multi sensor data from both Landsat and Sentinel-2 Earth Observation missions as both have shown to offer good accuracy performance concerning vegetation detection [9]. We present the analyzed SITS in Section II, and we detail the method used in order to extract the discovered evolution patterns in Section III. Section IV presents the interpretation of the results in the analyzed period. Conclusions 
and future research proposals are given in Section V.

\section{DATA PRESENTATION}

From the USGS Earth Explorer platform [10] we obtained a dataset of more than 400 acquisitions over Bucharest, Romania, spanning a period of forty years, from 1975 until 2016. The data is provided by multiple Earth Observation missions such as: Landsat 2 MSS (Multispectral Scanner System), Landsat 3 MSS, Landsat 4 MSS and TM, Landsat 5 MSS and TM, Landsat 7 ETM+, Landsat 8 OLI/TIRS and Sentinel-2 MSI. The data is partially or fully cloud-free and has an uneven temporal distribution. We analyzed the properties of each sensor used in the mentioned EO missions and we observed that Sentinel-2 MSI, Landsat 8 OLI/TIRS, Landsat 7 ETM+ and Landsat 4 and 5 TM sensors have almost identical spectral spans for the visible bands (red, green and blue), near infrared (NIR) and shortwave-infrared (SWIR) bands. Also, apart from Sentinel-2 MSI, which has a spatial resolution of $10 \mathrm{~m}$, all the previously mentioned Landsat missions have a spatial resolution of $30 \mathrm{~m}$ for these bands.

We chose to create and analyze a SITS which starts with 1984 because of the higher number of acquisitions available during summer and due to the fact that data acquired prior to this year (with the Landsat 2, 3, 4 and 5 MSS) has a smaller spatial resolution $(60 \mathrm{~m} \times 60 \mathrm{~m}$ per pixel). Also we decided to limit our analysis to the Landsat data, and use the Sentinel2 MSI acquisitions to verify the obtained results. For each analyzed year we required two cloud free summer acquisitions for our method to work. Considering the temporal distribution of the existing data and using the system presented in [11] we chose the years with a higher number of acquisitions and we chose eight distinct years (1984, 1987, 1991, 1994, 2001, 2006, 2011 and 2016) with relative similar time spans between them.

\section{USED METHOD}

Considering the spatial resolution of the Landsat data the land cover classes which can be observed are vegetation, build up and water bodies. We were interested in the way they developed in the 1984-2016 period. Our approach is to estimate surfaces covered by each of the previously mentioned classes using different spectral indexes such as NDVI (for vegetation), NDBI (for build up) and MNDWI (for water).

The overall method used to extract information regarding the land cover classes of interest is given in Fig. 1. We start by querying our downloaded dataset for $100 \%$ cloud free acquisitions over the POI, represented by the administrative area of Bucharest, Romania, presented in Fig. 2a. The retrieved data goes through a preprocessing step in which atmospheric corrections are made, the bands which are required in the calculation of spectral indexes are selected and clipped to a smaller area similar to the one presented in Fig. 2a.

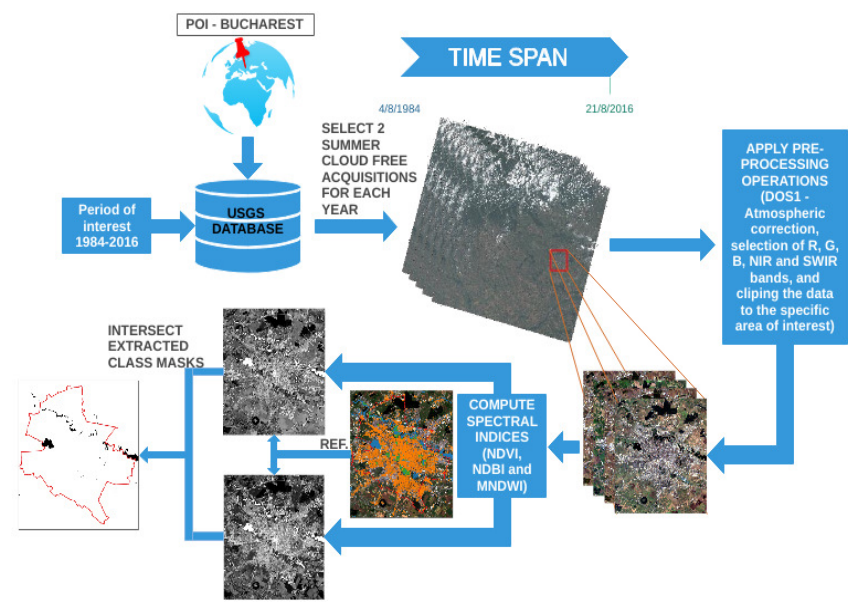

Fig. 1: Processing steps needed in order to obtain information regarding a certain land cover class coverage area from raw data.

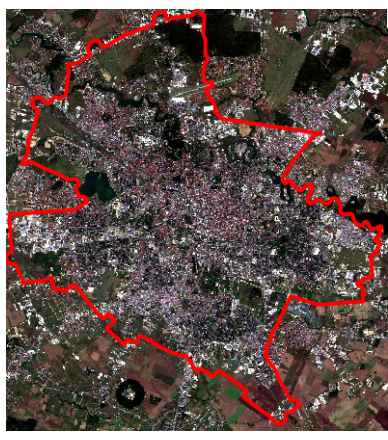

(a)

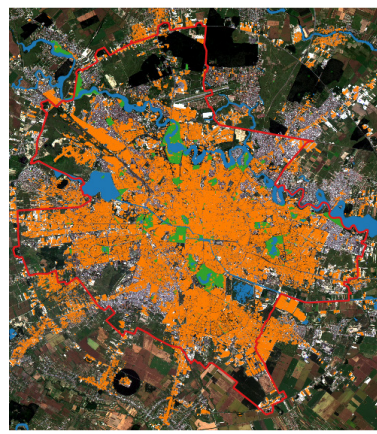

(b)
Fig. 2: Administrative area of Bucharest, Romania, represented by the red line (a). Data used as reference in determining the limits for the spectral indexes( blue - water bodies, green - public parks and orange - buildings)(b).

In the context of not having ground measured data the method used to make the atmospheric corrections is the DOS1 (Dark Object Subtraction 1)[12] method. The bands retained from each acquisition are the Red, Green, Blue, Near Infrared and Shortwave-Infrared bands. The data is clipped to a surface large enough to cover the POI and to reduce the computational costs. For each acquisition we compute the NDVI, NDBI, and MNDWI spectral indexes using the required bands for each type of sensor.

Because the data comes from multiple sensors, and considering that the distribution of values for the spectral indexes can vary between them, several reference areas are used for each of the analyzed land cover classes. The reference areas are unchanged in the 1984 to 2016 analyzed period and are represented by parks, lakes and old buildings which are shown together with all similar object classes in Fig. 2 b. The 


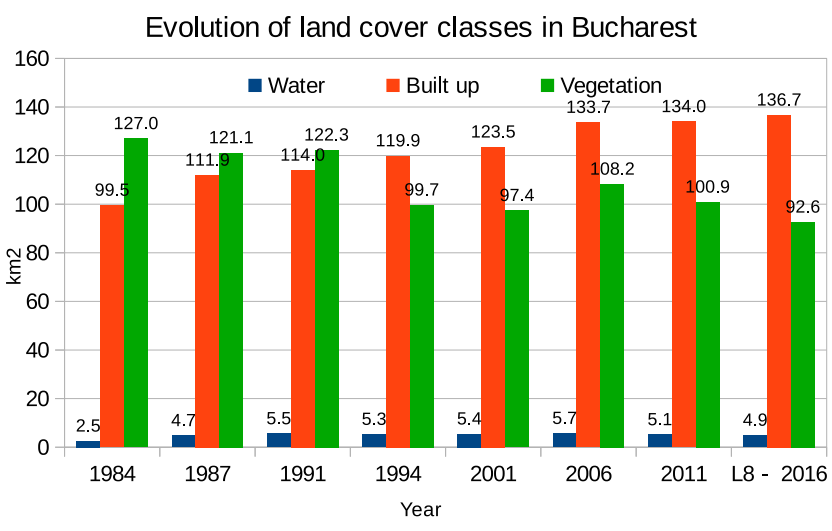

Fig. 3: Bucharest total surface $\left(\mathrm{km}^{2}\right)$ coverege from 1984 until 2016 by water (blue), built up (orange) and vegetation (green).

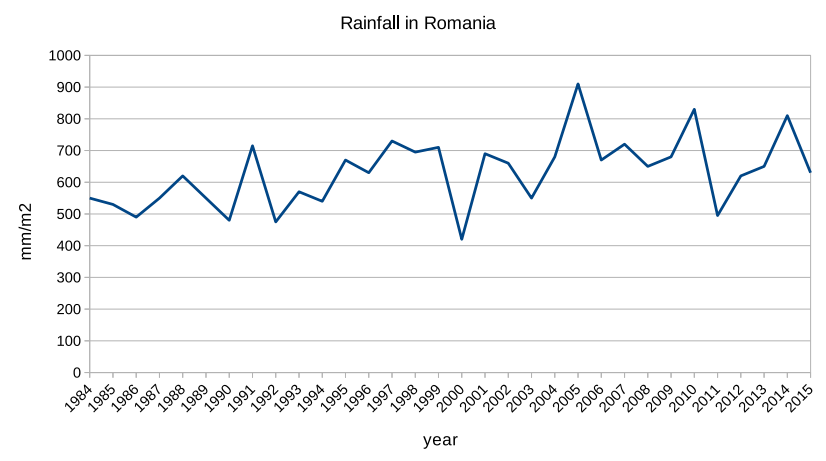

Fig. 4: Average rainfall $\left(\mathrm{mm} / \mathrm{m}^{2}\right)$ per year in Romania from 1984 until 2015.

shape files which helped us outline the areas of interest are provided by GEOFABRIK [13]. All of the pixels from the computed NDVI, NDBI and MNDWI which resided (totally or partially) in the reference areas were used to determine the minimum value of each type of spectral index from which the land cover class will be considered. Considering that the used data has a spatial resolution of $30 \mathrm{~m}$ (for the Landsat data) or $10 \mathrm{~m}$ (for Sentinel-2 data), we tried to reduce the uncertainty of the monitored land cover classes by intersecting the results of land cover masks obtained from two summer acquisitions.

The last step consists in retrieving the total pixels of the obtained land cover class mask which reside in the administrative area of Bucharest (red boundary shown in Fig. 2a). The total number is multiplied by the surface area covered by each pixel, which is $900 \mathrm{~m}^{2}$ for the Landsat data and $100 \mathrm{~m}^{2}$ for the Sentinel-2 data.

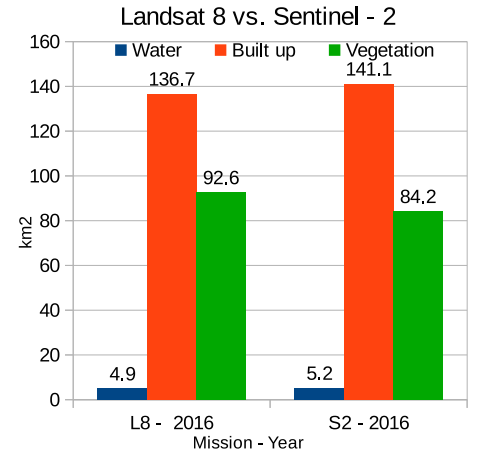

Fig. 5: Comparison, side by side, of total land cover surface of classes water, built up and vegetation obtained using data from Landsat 8 OLI/TIRS versus Sentinel-2 MSI.

\section{RESULTS AND INTERPRETATION}

The total surface area covered by each of the three classes (water, build up and vegetation) for each of the eight years can be observed in Fig. 3. The obtained values for the NDVI and MNDWI can be influenced by the volume of rainfall. Taking this in consideration we also present the national average rainfall evolution between 1984 and 2015 in Fig. 4 in order to help better understand the results. This data has been obtained from the Romanian National Meteorological Administration [14]. As it can be observed from Fig. 3 and Fig. 4 there is a correlation between the values obtained for vegetation and water. In 1991 and 2006 the increased quantity of rainfall (more than $120 \%$ and $150 \%$ of the national average) influenced the growth of vegetation and the size of water bodies which in turn translated into increased total surfaces for the two classes.

Previous to 1989 most of the construction projects undergone in Bucharest were planed at a great scale, some of which where the artificial "Morii" accumulation lake added a total of $2.46\left(\mathrm{~km}^{2}\right.$ to the total water land cover. This was also observed from our results. The construction of the lake started in 1985 and ended in august 1986 when water was let in. Other major projects include the current Parliament Palace which was started in 1984 and partially (exterior and a portion of the interior) finished in 1990. This was undergone in parallel with the construction of large residential areas made up of mostly 10 stories concrete buildings. These were undergone over previous residential areas made up of compact lots of houses.

In the analyzed period we observed an overall trend consisting in the increase of the built up area and the decrease of the vegetation land cover surfaces. This can be attributed to the increase of the population residing in Bucharest. Vegetation was in decline as the city started to expand outwards with low density residential areas (mostly) as the price of apartments increased. The 2008 economic crisis influenced 
the overall growth of the build up land cover, but during this period most of the projects were blocked which can be observed in the relative stagnation of total covered surface between 2006 and 20011.

In order to evaluate our results we used the Sentinel-2 data which has a greater spatial resolution and overlaps the Landsat 8 data for the year 2016 from our SITS. Analyzing the results we observed a slight increase in the total build up surface and a decrease of the total land cover area of vegetation. Also a slight increase of the water covered areas can be observed in Fig. 5 due to a better representation of the water bodies found mostly in the north and north-east part of Bucharest. These consist mostly of sinuous lakes which are harder to be captured using a sensor with a spatial resolution of $30 \mathrm{~m}$.

\section{CONCLUSIONS}

In the administrative area of Bucharest, the vegetation class presents a decreasing trend during the studied period in detriment of the build up. The overall surface covered by water bodies doubled in size around 1989 followed by a relative stagnation afterwards. The build up surfaces have increased mostly with high density areas required by the migrating population. Bucharest is currently one of the most densely populated capitals in Europe. This results in a decrease in the quality of life.

The values for the vegetation and water covered surfaces can be influenced by the quantity of rainfall which has also can be observed in our results. The used method can be used on SITS created from multiple satellite missions and sensors as long as there are some sort of reference areas for the sought classes.

\section{REFERENCES}

[1] "United nations, world urbanization prospects.," http: / /data.worldbank.org/indicator/ SP . URB . TOTL. IN . \\ZS?end=2015 \\&start= 1960, 2016, [Online; accessed 22-December-2017].

[2] C. Huang, Q. Chen, S. Ying, F. Zhao, Y. Shao, W. Yu, J. Chen, F. Liu, X. Xu, and J. Li, "An analysis on the coupling relationship between urban vegetation and land surface temperature in hangzhou based on aster imagery," in 2009 IEEE International Geoscience and Remote Sensing Symposium, July 2009, vol. 3, pp. III338-III-341.

[3] J. Zhou, Y. Huang, and B. Yu, "Mapping vegetationcovered urban surfaces using seeded region growing in visible-nir air photos," IEEE Journal of Selected Topics in Applied Earth Observations and Remote Sensing, vol. 8, no. 5, pp. 2212-2221, May 2015.
[4] D. Tanre, B. N. Holben, and Y. J. Kaufman, "Atmospheric correction against algorithm for noaa-avhrr products: theory and application," IEEE Transactions on Geoscience and Remote Sensing, vol. 30, no. 2, pp. 231-248, Mar 1992.

[5] M. E. Brown, J. E. Pinzon, K. Didan, J. T. Morisette, and C. J. Tucker, "Evaluation of the consistency of long-term ndvi time series derived from avhrr,spotvegetation, seawifs, modis, and landsat etm+ sensors," IEEE Transactions on Geoscience and Remote Sensing, vol. 44, no. 7, pp. 1787-1793, July 2006.

[6] D. Jeevalakshmi, S. N. Reddy, and B. Manikiam, "Land cover classification based on ndvi using landsat8 time series: A case study tirupati region," in 2016 International Conference on Communication and Signal Processing (ICCSP), April 2016, pp. 1332-1335.

[7] L. A. S. Romani, R. R. V. Gonalves, B. F. Amaral, D. Y. T. Chino, J. Zullo, C. Traina, E. P. M. Sousa, and A. J. M. Traina, "Clustering analysis applied to ndvi/noaa multitemporal images to improve the monitoring process of sugarcane crops," in 2011 6th International Workshop on the Analysis of Multi-temporal Remote Sensing Images (Multi-Temp), July 2011, pp. 3336.

[8] T. Costchioiu, R. Constantinescu, and M. Datcu, "Multitemporal satellite image time series analysis of urban development in bucharest and ilfov areas," in 2014 10th International Conference on Communications (COMM), May 2014, pp. 1-4.

[9] M. Sibanda, O. Mutanga, and M. Rouget, "Discriminating rangeland management practices using simulated hyspiri, landsat 8 oli, sentinel $2 \mathrm{msi}$, and venus spectral data," IEEE Journal of Selected Topics in Applied Earth Observations and Remote Sensing, vol. 9, no. 9, pp. 3957-3969, Sept 2016.

[10] "Usgs, earth explorer," http: / / earthexplorer. usgs.gov/.

[11] A. C. Grivei and M. Datcu, "Hypermine - an earth observation spatio-temporal data mining system," in 2015 23rd Telecommunications Forum Telfor (TELFOR), Nov 2015, pp. 906-909.

[12] M. Moran, R. Jackson, P. Slater, and P. Teillet, "Evaluation of simplified procedures for retrieval of land surface reflectance factors from satellite sensor output," $R e$ mote Sensing of Environment, vol. 41, no. 5, pp. 69-184, 1992.

[13] ," http: / / download.geofabrik.de/.

[14] ," http: / / www . meteoromania.ro/anm2/. 